\title{
Relationships between test anxiety, self-regulation and strategies for coping with stress, in professional examination candidates
}

\author{
Jorge Amate-Romera ${ }^{1,2}$, and Jesús de la Fuente $3,2, *$ \\ 1 Primary school teacher. Department of Education, Andalucia (Spain). \\ 2 Research Group HUM-746. University of Almeria (Spain). \\ 3 School of Education and Psychology, University of Navarra (Spain).
}

\begin{abstract}
Título: Relaciones entre ansiedad evaluativa, autorregulación y estrategias de afrontamiento del estrés en universitarios opositores.

Resumen: El objetivo de la investigación fue establecer relaciones de asociación, interdependencia y predicción estructural entre las variables ansiedad evaluativa, autorregulación y estrategias de afrontamiento del estrés. E marco teórico de referencia fue el modelo de Competencia para Aprender, Estudiar y Rendir bajo Estrés (CAERE). Participaron 142 estudiantes, que se estaban preparando oposiciones en academias de Almería (España) para obtener plaza como maestros en centros públicos. Para la recogida de datos se administraron cuestionarios escritos previamente validados. El diseño fue ex post-facto lineal, con análisis de asociación bivariada, inferenciales (ANOVAs y MANOVAs) y de predicción estructural. Los resultados mostraron una relación negativa entre la ansiedad evaluativa y la autorregulación, especialmente en los estudiantes con alta emocionalidad, con un impacto negativo para la toma de decisiones. También se encontraron relaciones positivas entre la ansiedad evaluativa y las estrategias de afrontamiento del estrés. Por último, se constató la relación de predicción positiva entre la autorregulación y las estrategias de afrontamiento, a la vez que los análisis asociativos e inferenciales destacaron el papel de las metas como determinantes de las estrategias usadas para afrontar el estrés, especialmente, las referidas a la focalización en la resolución de problemas. Se discuten los resultados y se establecen implicaciones para las mejoras de estos procesos en los estudiantes opositores.

Palabras clave: Ansiedad evaluativa. Autorregulación. Estrategias de afrontamiento. Estrés académico. Estudiantes universitarios opositores.
\end{abstract}

\section{Introduction}

The transition from academics to the professional world sometimes involves going through a selective examination process, especially when the demand for jobs is greater than the number of positions available. These examinations require an extended period of intellectual preparation, but they also require emotional preparation (Thomas et al., 2017). A successful outcome on these competitive examinations involves performing under conditions of prolonged stress, as well as coordinating different goal-directed behaviors. In this context, we must emphasize the importance of variables like self-regulation and stress management in order to obtain the desired outcome on these types of examinations (Ariani, 2016). Such contexts, however, have not received much research analysis, despite their emotional weight and personal impact on students. For this reason, the present research report underscores certain important relationships to be taken into consideration. It also seeks to contribute further evi-

* Correspondence address [Dirección para correspondencia]: Jesús de la Fuente. School of Education and Psychology, University of Navarra, 31009 Pamplona (Spain).E-mail: jdlfuente@,unav.es

(Article received: 21-01-2020, revised: 09-12-2020, accepted: 14-01-2021)
Abstract: The research objective was to establish relationships of association, interdependence and structural prediction between the variables of test anxiety, self-regulation and stress coping strategies. The theoretical framework of reference was the Competence for Studying, Learning and Perform ing under Stress (CSLPS) model. Participating were 142 students who were preparing for professional examinations to attain a post as public school teacher (primary education), enrolled at academies in Almería (Spain) for this purpose. Previously validated questionnaires were administered for data collection. The study design was linear ex post-facto, with bivariate, in ferential analyses of association (ANOVAs and MANOVAs) and of structural prediction. Results showed a negative relationship between test anxiety self-regulation, especially in students with high emotionality, and a negative impact on decision making. Positive relationships were found between test anxiety and strategies for coping with stress. Finally, a positive predic tive relationship was verified between self-regulation and coping strategies, while associative and inferential analyses highlighted the role of goals as determining factors in strategies used for coping with stress, especially strategies that focus on problem solving. Results are discussed and implications for improving these processes in professional examination candidates are established.

Keywords: Test anxiety. Self-regulation. Coping strategies. Academic stress. Students professional examination candidates.

dence to the line of research of our research team: extending our knowledge of how different variables impact learning, as a function of contextual stress (de la Fuente-Arias \& AmateRomera, 2019; de la Fuente et al., 2018).

\section{Learning under stressful conditions}

From the constructivist perspective, learning involves constructing new meanings about reality (Torre \& Vidal, 2017). However, this learning usually takes place in an institutional context and with certain intentionality, involving the interaction of multiple dimensions, such as learner characteristics (experiences, expectations and beliefs) and characteristics of the situation (demands, models of teaching-learning, social environment). These dimensions undoubtedly influence learning processes and outcomes, which in turn have a reciprocal effect on these same dimensions. Alt (2015) demonstrated, in students of Higher Education, how the method of learning influenced academic self-efficacy, that is, students' belief about their capacity to regulate their own learning, and how this belief in turn affected motivational processes and performance.

On the other hand, our body makes an adaptive response to stress that arises from the environmental demands of dif- 
ferent circumstances; the effects over time may eventually become detrimental to our health (Cote \& García, 2016). In the educational sphere, environmental demands are usually educational processes and assessment, as perceived by the student. While research on stress has historically emphasized other spheres, attention to stress within the educational context has risen in recent decades (Concerto et al., 2017; de la Fuente et al., 2016; Mehmet \& Watson, 2017).

Today, there are models that seek to explain learning and performance in situations that involve intense stress over time, such as in the case of preparing competitive examinations to gain professional placement. The Competency Model of Studying, Learning and Performing under Stress (CSLPS) (de la Fuente, 2015; de la Fuente et al., 2014; Banerjee et al., 2019) integrates different presage, process and product variables that interact to form a competency that enables students to more successfully face this type of situation. Highly current research variables from the world of Educational Psychology are incorporated within this framework (GarzónUmerenkova et al., 2018).

\section{Test anxiety}

This variable has been defined as the negative emotion that some students experience in a testing situation, an intense, irrational fear whose most direct consequence is poorer academic performance than what could be expected from their effort and competencies, and which can even be manifest in avoidance behaviors (Escolar \& Serrano, 2014). Prior evidence indicates that test anxiety can be an explanatory cause of learning difficulties, low achievement and loss of cognitive resources (Putwain et al., 2015). This construct in turn comprises two large components: worry and emotionality (Burdwood et al., 2016; Pekrun, 2016).

\section{Personal self-regulation}

This variable was defined by Brown (1998) as the ability to plan, guide and flexibly control one's own behavior in order to adapt to changing circumstances. The concept has traditionally been applied to a number of contexts, including work, healthcare, and the organizational world (Karoly et al., 2005). When applied to the academic sphere, it has been defined as activity oriented toward planning and managing time and effort, in order to meet academic goals (de la Fuente et al., 2007; Muis et al., 2018). In this regard, self-control, one of the predominant characteristics of self-regulated behavior (de Ridder et al., 2012), has proven to be a better predictor of academic achievement than intelligence quotient (IQ) (Duckworth et al., 2012). Recently, personal self-regulation has also been shown to be important in healthcare, academic achievement, and in avoiding behaviors like procrastination (Garzón-Umerenkova et al., 2018; Pichardo et al., 2018).

\section{Strategies for coping with stress}

This variable is linked to behaviors that individuals use to avoid the negative consequences of interacting with situations of academic stress. Research indicates the existence of two types of strategies, those that focus on emotions and those that focus on the problem (Lazarus \& Folkman, 1984; Modecki et al., 2017; Nielsen \& Knardahl, 2014). While the former mainly address the symptoms and consequences of stress, the latter focus on the causes that created the stress, and represent a more functional perspective. In fact, problem-focused strategies have been related to resilience, deep learning approach, and academic achievement in university students (de la Fuente, Fernández-Cabezas et al., 2017). Other current research studies emphasize the influence of the stressful contexts themselves on the use of these strategies (de la Fuente et al., 2016).

\section{Objectives and hypotheses}

Based on this problem area and the prior evidence, the general objective was to describe relationships of association, interdependence, and prediction, between the total scores, dimensions and factors of the study variables. Specifically, the following bypotheses were posed:

1) The variable test anxiety and its factors will have significant, negative relationships of bivariate association and interdependence with the variable personal self-regulation and its factors. There is prior evidence that the worry factor of anxiety is negatively related to personal selfregulation (de la Fuente, López et al., 2017), even though this relationship is yet to be tested in professional examination candidates.

2) The variable test anxiety and its factors will have significant, positive relationships of bivariate association and interdependence with the variable coping strategies, its dimensions and its factors. Prior evidence shows test anxiety in a negative association with the use of problemfocused coping strategies, and positive association with emotion-focused strategies (de la Fuente, GarcíaTorrecillas et al., 2015).

3) The variable personal self-regulation and its factors will have significant, positive relationships of association and interdependence with the variable coping strategies, its dimensions and factors. Prior studies have shown a relationship between the two variables (de la Fuente, Sander et al., 2015).

4) The test anxiety variable will be a negative and significant structural predictor of personal self-regulation, and a positive, significant structural predictor of coping strategies. The personal self-regulation variable, in turn, will be a significant, positive structural predictor of coping strategies. 


\section{Method}

\section{Participants}

A total of 142 subjects participated in this research study. All of them were seeking to obtain posts as primary school teachers and were preparing for the pertinent selective examinations at academies in the city of Almería (Spain). Participating academies were randomly selected from among those that offered this type of training in the local area. The corresponding permissions were requested from their directors, and access was granted to the groups and individuals enrolled in the corresponding program. The sample was predominantly female $(n=104)$, compared to male $(n=38)$; this is consistent with the reference population. Ages ranged from 21 to 45 years $(M=24.50 ; S D=4.70)$. The sample showed practically equal distribution of candidates who had not previously sat for these exams, and candidates who had sat for these exams on prior occasions. The latter had sat for these exams on 1 to 5 past occasions. For reasons unrelated to the research variables (usually absence from class), some subjects did not answer all the questionnaires. We worked with all the available data, ignoring missing data, which represented less than $5 \%$. This explains small variations that may be observed in the sample sizes.

\section{Instruments}

Test Anxiety Inventory, TAI-80 (Sarason, 1980). This instrument was used to measure the test anxiety variable. It contains 20 Likert-type items, where the individual must indicate how often he or she experiences certain customary emotions. Confirmatory factor analysis showed a structure comprising two factors: emotionality and worry, each composed of 10 items. Construct validity is acceptable (Chi-squared = 524.674, $d f=169$, NFI Delta $1=.867$, RFI $=.910$, IFI $=$ .929, TLI $=.938$, CFI $=.925$, RMSEA $=.062$, HOELTER $.05=208$, HOELTER $.01=223)$, as is total instrument reliability $(\alpha=$.917). Data findings are similar to those of other authors and on several occasions (de la Fuente, Sander et al., 2017; Yager, 2008).

Spanish Short Self-Regulation Questionnaire, SSSRQ (Pichardo et al., 2014). This questionnaire is an adaptation of the original Self-Regulation Questionnaire (Brown et al., 1999), further synthesized and contextualized. This version contains 17 items and 4 factors: goals, perseverance, decision making and learning from mistakes. The questionnaire is properly validated and its structure has been shown to be consistent: Construct validity is acceptable (Chi-Square $=250.83, d f=112$, CFI $=$ .95 , GFI $=.94$, AGFI $=.96$, RMSEA $=.059)$. It has an acceptable validity and reliability values [total $(\alpha=.86)$; goal setting-planning $(\alpha=.79)$, perseverance $(\alpha=.78)$, decision making $(\alpha=.72)$ and learning from mistakes $(\alpha=.72)$ ]. Its psychometric properties are verified in Pichardo et al. (2014) and more recently in Garzón-Umerenkova et al. (2017) and Pichardo et al. (2018).
Short Questionnaire on strategies for coping with stress, ShortEEC (de la Fuente, 2014). This questionnaire is derived from the original version (Chorot \& Sandín, 1993) and later validated for university students (de la Fuente et al., 2014). While the original instrument contains 90 items, the validated version produced a first-order factor structure containing 64 items, and second-order factor analysis reduced these to 10 factors and 2 significant dimensions, with acceptable validity $($ Chi-squared $=878.750 ; d f(77-34)=43, p=.00$; NFI $=.901 ;$ RFI $=.945 ;$ IFI $=.903$, TLI $=.951$, CFI $=.903)$. Cronbach reliability values for the complete scale were $.93(\alpha$ $=.93$ and $\alpha=.90$ for the subscales, respectively), while the Spearman-Brown indicator was .84 and Guttman was .80 . The factors of Dimension 1 (EECD1 Emotion-focused strategies) are: EECD1F1-Preparing for the worst, EECD1F2-Reducing anxiety and avoidance; EECD1F3-Fantasy distraction; EECD1F4Resigned acceptance and EECD1F5-Emotional venting and isolation. The factors of Dimension 2 (EECD2 Problem-focused strategies) are: EECD2F1-Communicating feelings and social support, EECD2F2-Self-instructions; EECD2F3-Positive reappraisal and firmness; EECD2F4-Help seeking and EECD2F5-Seeking alternative reinforcement.

\section{Procedure}

Questionnaires were administered in pen and paper format in the subjects' usual preparatory classes for the competitive examinations. The instruments were applied over three sessions, one for each questionnaire. Prior to application, a general explanation was given about the importance of the research and how their data would be handled, and voluntary participation was requested via informed consent -- but without entering into detail about the study objectives or hypotheses, so as not to influence their responses.

The data obtained from subjects' responses was handled with confidentiality, and Psychology ethical and deontological principles were followed. Data were processed as a whole (not identified by individual) and were stored at the University of Almeria. The Bioethics Committee of this university approved both the project and the instruments.

\section{Design and data analyses}

The research was carried out using an ex post facto, linear design, assigning subjects to their levels of the independent variable after the questionnaires were administered. The structure, validity and reliability of the instruments were validated by confirmatory factor analysis and Cronbach's alpha statistic. Model fit was assessed by first examining the chisquare to degrees of freedom ratio as well as the Comparative Fit Index (CFI) and Normed Fit Index (NFI), Incremental Fit Index (IFI), and Relative Fit Index (RFI). Ideally, these should be greater than .90 . We also used the Hoelter Index to determine adequacy of sample size (Tabachnick \& Fidell, 2001). Pearson's bivariate correlation was the method used for the associative analyses. Distribution of the subjects 
into levels (low-medium-high) was carried out using $\mathrm{K}$ means clustering analysis, for the independent variable totals and for their dimensions and/or factors. The inferential analyses included both ANOVA and MANOVA (post hoc: Sheffe). In all analyses, the significance index considered was .05. Finally, a structural prediction analysis or path analysis (SEM; with similar indices, already exposed) was conducted in order to analyze both direct and indirect effects among the research variables. The above analyses were performed using IBM SPSS (v.22) and AMOS (v.22).

\section{Results}

Association and interdependence relationships between the variable test anxiety and the variable personal self-regulation (Hypothesis 1).

With regard to relationships of association, a significant negative correlation was observed between the total variable of test anxiety and the total variable of personal self-regulation $(r$ $=-.538 ; p<.05)$, and a very significant association found with the decision-making factor of personal self-regulation $(r$ $=-.630 ; p<.01)$. A significant negative correlation was also observed between the emotionality factor of the test anxiety variable, and the total variable of personal self-regulation $(r=$ $.494 ; p<.05)$, as well as between emotionality and the decision- making factor of the self-regulation variable $(r=-.543 ; p<$ .01). A significant negative correlation was also observed between the emotionality factor of the test anxiety variable, and the total variable of personal self-regulation $(r=-.494 ; p<.05)$, as well as between emotionality and the decision-making factor of self-regulation $(r=-.543 ; p<.01)$.

As for interdependence relationships, low-medium-high levels of the Independent Variable (IV) test anxiety determined significant effects on the total Dependent Variable (DV) personal self-regulation $\left[F(2,139)=5.246, p<.05\right.$, eta $^{2}=$ .412 , observed power $=.747$; Post hoc: $1>2, p<.05]$. In addition, they also determined significant effects on the decision making factor $\left[F(2,139)=4.189, p<.05\right.$, eta ${ }^{2}=.358$, observed power $=.644$; Post hoc: $1>3, p<.05]$. See Table 1 .

On the other hand, low-medium-high levels in the IV emotionality, one of the factors of test anxiety, determined significant effects on the total DV personal self-regulation $[F(2$, $139)=4.008, p<.05$, eta $^{2}=.334$, observed power $\left.=.630\right]$. In addition, they also determined significant effects on the decision making factor $\left[F(2,139)=5.099, p<.05\right.$, eta ${ }^{2}=.375$, observed power $=.746$; Post hoc: $1>3, p<.05]$. See Table 1 .

By contrast, low-medium-high levels of the IV worry, the other factor of test anxiety, did not produce significant effects on the total dependent variable personal self-regulation, nor on its factors.

Table 1

Significant interdependence relationships between test anxiety (IV) and personal self-regulation (DV).

\begin{tabular}{|c|c|c|c|}
\hline & \multicolumn{3}{|c|}{ Total test anxiety } \\
\hline & $\begin{array}{c}\text { Low (1) } \\
n=51\end{array}$ & $\begin{array}{c}\text { Medium (2) } \\
n=50\end{array}$ & $\begin{array}{c}\text { High (3) } \\
n=41\end{array}$ \\
\hline \multicolumn{4}{|l|}{ Personal self-regulation } \\
\hline Total personal self-regulation & $3.65(.34)$ & $3.07(.46)$ & $3.00(.15)$ \\
\hline \multicolumn{4}{|l|}{ Personal self-regulation factors } \\
\hline \multirow[t]{3}{*}{ Decision making } & $3.40(.54)$ & $3.10(.50)$ & $2.40(.35)$ \\
\hline & \multicolumn{3}{|c|}{ Emotionality (F1 - Test anxiety) } \\
\hline & $\begin{array}{c}\text { Low (1) } \\
n=49\end{array}$ & $\begin{array}{c}\text { Medium (2) } \\
n=52\end{array}$ & $\begin{array}{c}\text { High (3) } \\
n=41\end{array}$ \\
\hline \multicolumn{4}{|l|}{ Personal self-regulation } \\
\hline Total personal self-regulation & $3.85(.29)$ & $3.19(.45)$ & $3.00(.15)$ \\
\hline \multicolumn{4}{|l|}{ Personal self-regulation factors } \\
\hline Decision making & $3.80(.60)$ & $2.94(.56)$ & $2.40(.35)$ \\
\hline
\end{tabular}

Association and interdependence relationships between the variables stress coping strategies and test anxiety (Hypothesis 2)

Regarding relationships of association, a significant positive correlation was observed between the total variable of test anxiety and the total variable of coping strategies $(r=.182 ; p$ $<.05)$. Similarly, the total for the test anxiety variable was positively correlated to the following factors of the coping strategies variable: EECD1F4-Resigned acceptance $(r=.210 ; p<.01)$ and EECD1F5-Emotional venting and isolation $(r=.282 ; p<$ $.001)$.

The emotionality factor of the test anxiety variable was posi- tively correlated only with the following factors of the coping strategies variable: EECD1F4-Resigned acceptance $(r=.204 ; \mathrm{p}<$ $.01)$ and EECD1F5-Emotional venting and isolation $(r=.237 ; \mathrm{p}$ $<.01)$.

Regarding the worry factor of the test anxiety variable, a significant, positive correlation was observed with the total variable of coping strategies $(r=.214 ; p<.05)$. Moreover, the worry factor also correlated positively with the following factors of the coping strategies variable: EECD1F4-Resigned acceptance $(r=.231 ; \mathrm{p}<.01)$ and EECD1F5-Emotional venting and isolation $(r=.324 ; p<.001)$.

Regarding interdependence relationships, low-mediumhigh levels of the IV test anxiety did not determine significant 
effects on the total DV stress coping strategies, nor on any of its dimensions. Nonetheless, it did determine significant effects on the following factors: EECD1F4-Resigned acceptance $[F(2$, $139)=4.528, p<.01$, eta ${ }^{2}=.062$, observed power $=.764$; Post hoc: $1<3, p<.05]$ and EECD1F5-Emotional venting and isolation $\left[F(2,139)=6.508, p<.01\right.$, eta ${ }^{2}=.086$, observed power $=.902$; Post hoc: $1<3, p<.01]$. See Table 2 .

Similarly, low-medium-high levels of the IV emotionality, one of the factors of test anxiety, did not produce significant effects on the total DV stress coping strategies or on any of its dimensions. Nonetheless, it did determine significant effects on the following factors: EECD1F4-Resigned acceptance $[F(2$, $139)=4.643, p<.01$, eta $^{2}=.059$, observed power $=.775$;
Post hoc: $1<3, p<.05]$ and EECD1F5-Emotional venting and isolation $\left[F(2,139)=4.658, p<.01\right.$, et ${ }^{2}=.059$, observed power $=.777$; Post hoc: $1<3, p<.01]$. See Table 2 .

By contrast, low-medium-high levels of the IV worry, the other factor of test anxiety, did determine significant effects on the total DV coping strategies $[F(2,139)=3.057, p<.05$, eta $^{2}=.047$, observed power $\left.=.582\right]$ and on the following factors: EECD1F4-Resigned acceptance $[F(2,139)=3.034, p<$ .05 , eta $^{2}=.039$, observed power $=.580$; Post hoc: $1<3, p<$ $.05]$ and EECD1F5-Emotional venting and isolation $[F(2,139)=$ $6.281, p<.01$, eta $^{2}=.076$, observed power $=.892$; Post hoc: $1<3, p<.01]$. See Table 2 .

Table 2

Significant interdependence relationships between test anxiety (IV) and stress coping strategies (DV).

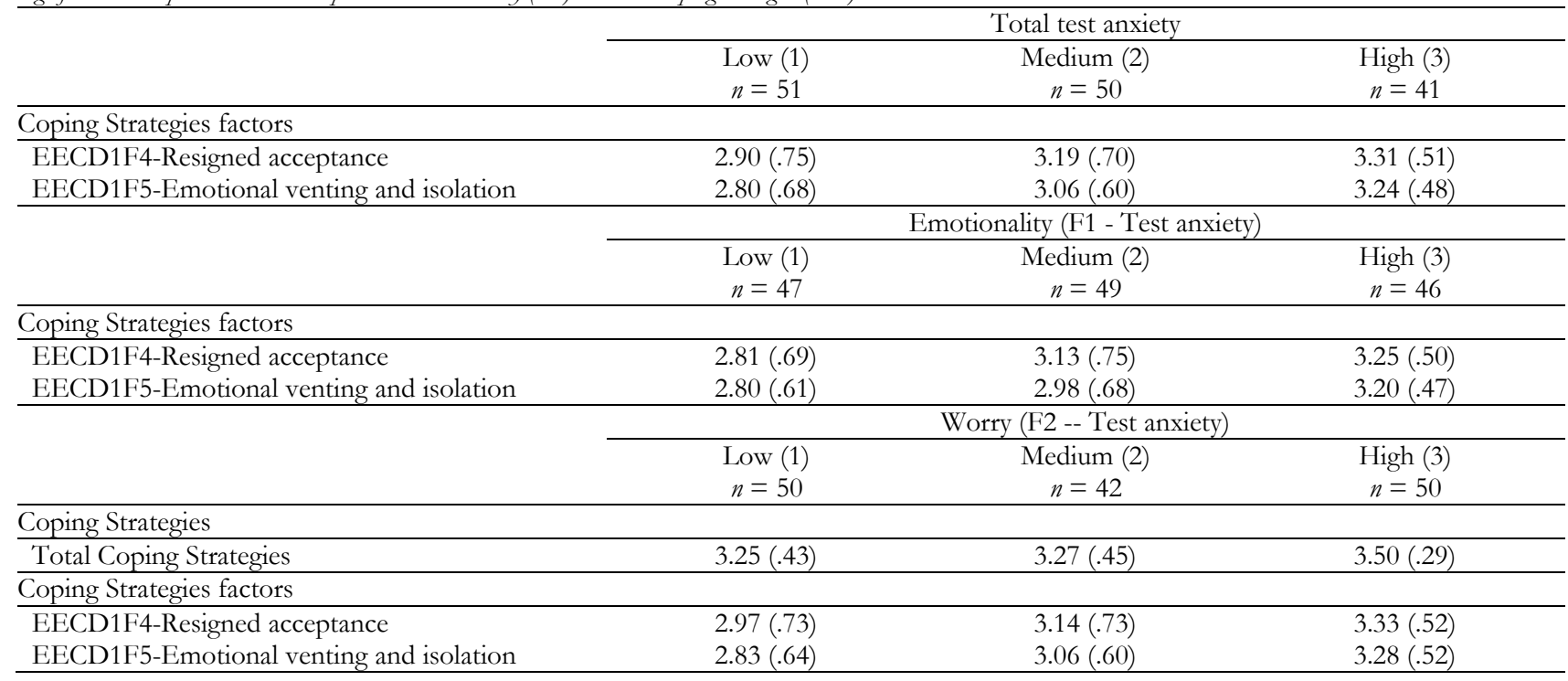

\section{Association and interdependence relationships be- tween the variables personal self-regulation and stress coping strategies (Hypothesis 3)}

Regarding relationships of association, personal selfregulation in general was not observed to have significant correlations with the total variable of coping strategies, nor with any of its dimensions or factors.

Regarding the goals factor of personal self-regulation, a significant, positive correlation was observed with the total variable of coping strategies $(r=.218$; $p<.05)$. Moreover, the goals factor also correlated positively with one factor of coping strategies, EECD2F5-Seeking alternative reinforcement $(r=$ $.213 ; p<.05)$.

The perseverance factor of personal self-regulation was positively correlated only with the following factors of the coping strategies variable: EECD2F2-Self-instructions $(r=.201 ; p$ $<.05)$ and EECD2F4-Help seeking $(r=.203$; $p<.05)$.

The decision making factor of personal self-regulation was correlated -negatively- with one of the coping strategies factors, EECD2F3-Positive reappraisal and firmness $(r=-.201 ; p<.05)$.
The learning from mistakes factor of personal self-regulation only correlated positively with coping strategies factor EECD1F2-Reducing anxiety and avoidance $(r=.297 ; p<.01)$.

Regarding interdependence relationships, low-mediumhigh levels of the IV personal self-regulation did not produce significant effects on the total dependent variable stress coping strategies, nor on any of its dimensions or factors.

More specifically, low-medium-high levels of the IV goals, one of the factors of personal self-regulation, determined a significant effects on the total DV stress coping strategies $[F(2,136)$ $=3.841, p<.05$, et ${ }^{2}=.078$, observed power $=.683$; Post hoc: $1<3, p<.05]$; as well as on one of its dimensions, problem-focused strategies $\left[F(2,136)=3.837, p<.05\right.$, eta ${ }^{2}=.075$, observed power $=.683$; Post hoc: $1<3, p<.05]$; and on the following factors: EECD1F3-Fantasy distraction $[F(2,136)=$ 3.722, $p<.05$, eta ${ }^{2}=.069$, observed power $=.670$; Post hoc: $1<3, p<.05]$, EECD1F5-Emotional venting and isolation $[F(2$, $136)=3.631, p<.05$, eta ${ }^{2}=.068$, observed power $\left.=.659\right]$, EECD2F2-Self-instructions $\left[F(2,136)=2.938, p<.05\right.$, eta ${ }^{2}=$ .057 , observed power $=.561]$, EECD2F4-Help seeking $[F(2$, 136) $=3.274, p<.05$, eta $^{2}=.062$, observed power $\left.=.610\right]$ 
and EECD2F5-Seeking alternative reinforcement $[F(2,136)=$ $3.341, p<.05$, et ${ }^{2}=.063$, observed power $=.620$; Post hoc: $1<3, p<.05]$. See Table 3 .

The low-medium-high levels of the IV perseverance, another factor of personal self-regulation, did not produce significant effects on the total, dimensions or factors of the dependent variable stress coping strategies. Low-medium-high levels of the IV decision making, another factor of personal self- regulation, produced significant effects on the single factor, EECD2F3-Positive reappraisal and firmness $[F(2,136)=3.436, p$ $<.05$, eta $^{2}=.066$, observed power $=.632$; Post hoc: $2>3, p$ $<.05$ ] of the coping strategies variable (See Table 3). Finally, low-medium-high levels of the IV learning from mistakes, another factor of personal self-regulation, did not produce significant effects on the total, dimensions or factors of the dependent variable stress coping strategies.

Table 3

Significant interdependence relationships between personal self-regulation (IV) and stress coping strategies (DV).

\begin{tabular}{|c|c|c|c|}
\hline & \multicolumn{3}{|c|}{ Goals (F1 -- Personal self-regulation) } \\
\hline & $\begin{array}{c}\text { Low (1) } \\
n=49\end{array}$ & $\begin{array}{c}\text { Medium (2) } \\
n=50\end{array}$ & $\begin{array}{c}\text { High (3) } \\
n=40\end{array}$ \\
\hline \multicolumn{4}{|l|}{ Coping Strategies } \\
\hline Total Coping Strategies & $2.37(.34)$ & $2.47(.25)$ & $2.58(.21)$ \\
\hline \multicolumn{4}{|l|}{ Dimensions of Coping Strategies } \\
\hline Problem-focused strategies & $2.61(.42)$ & $2.77(.28)$ & $2.86(.28)$ \\
\hline \multicolumn{4}{|l|}{ Factors of Coping Strategies } \\
\hline EECD1F3-Fantasy distraction & $2.00(.63)$ & $2.25(.43)$ & $2.35(.50)$ \\
\hline EECD1F5-Emotional venting and isolation & $2.05(.54)$ & $1.82(.33)$ & $2.07(.52)$ \\
\hline EECD2F2-Self-instructions & $2.86(.51)$ & $3.01(.36)$ & $3.12(.38)$ \\
\hline EECD2F4-Help seeking & $2.72(.76)$ & $3.03(.65)$ & $3.15(.52)$ \\
\hline \multirow[t]{3}{*}{ EECD2F5-Seeking alternative reinforcement } & $2.54(.50)$ & $2.73(.36)$ & $2.83(.44)$ \\
\hline & \multicolumn{3}{|c|}{ Decision making (F3 -- Personal self-regulation) } \\
\hline & $\begin{array}{c}\text { Low (1) } \\
n=48\end{array}$ & $\begin{array}{c}\text { Medium (2) } \\
n=51\end{array}$ & $\begin{array}{c}\text { High (3) } \\
n=40\end{array}$ \\
\hline \multicolumn{4}{|l|}{ Factors Coping Strategies } \\
\hline EECD2F3-Positive reappraisal and firmness & $2.98(.60)$ & $2.93(.46)$ & $2.64(.46)$ \\
\hline
\end{tabular}

\section{Structural linear relations (SEM) (Hypothesis 4)}

Graphic representation of the model. The graphic representation is presented in Figure 1.
The results of the structural analysis showed an acceptable model of relations between the different variables. See Table 4. 
Figure 1

Graphic representation of the structural model.

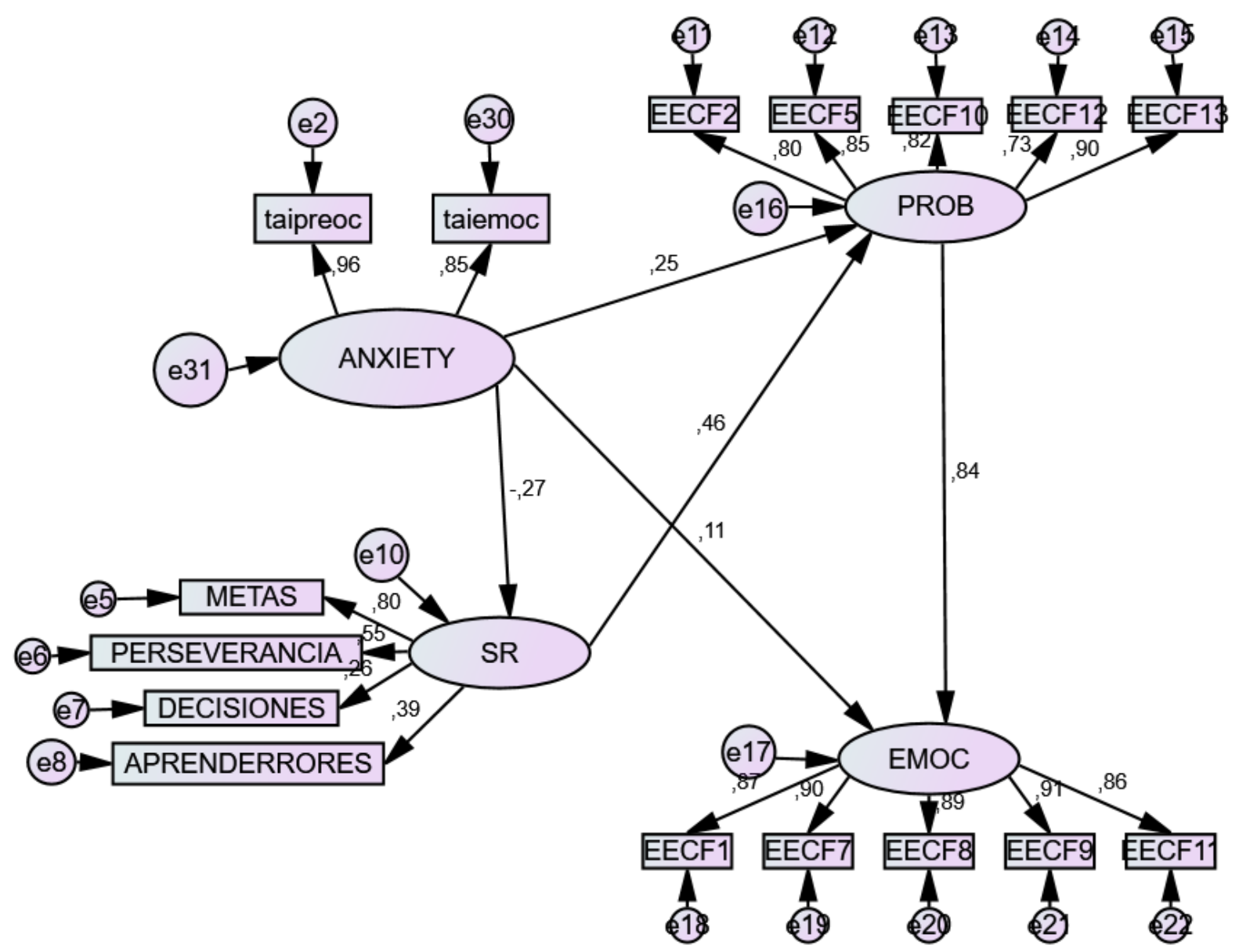

Note: ANXIETY = Test anxiety; SR = Self-regulation; $\mathrm{PROB}=$ problem-focused coping strategies; EMOC $=$ emotion-focused coping strategies; taiemoc $=$ Emotionality factor (var. test anxiety); taipreoc = Worry factor (var. test anxiety); METAS = goals factor (var. personal self-regulation); PERSERVERANCIA $=$ perseverance factor (var. personal self-regulation); DECISIONES $=$ decision making factor (var. personal self-regulation); APRENDERRORES = learning from mistakes factor (var. personal self-regulation); EECF2 = Factor EECD2F4-Help-seeking (var. stress coping strategies); EECF5 = Factor EECD2F2-Self-instructions (var. coping strategies); EECF10 = Factor EECD2F3-Positive reappraisal and firmness (var. coping strategies); EECF12 = Factor EECD2F1-Communicating feelings and social support (var. coping strategies); EECF13 = Factor EECD2F5-Seeking alternative reinforcement (var. coping strategies); EECF1 = Factor EECD1F3-Fantasy distraction (var. coping strategies); EECF7 = Factor EECD1F2-Reducing anxiety and avoidance (var. coping strategies); EECF8 = Factor EECD1F1-Preparing for the worst (var. coping strategies); EECF9 = Factor EECD1F5-Emotional venting (var. coping strategies); EECF11 = Factor EECD1F4-Resigned acceptance (var. coping strategies).

Table 4

Models of linear structural relations.

\begin{tabular}{lcccccccccc}
\hline \multirow{3}{*}{ Default model } & $\mathrm{Chi}^{2}$ & FG & $p<$ & NFI & RFI & IFI & TLI & CFI & HOELTER & RMSEA \\
\cline { 2 - 26 } & 605.761 & $(152-53): 99$ & .000 & .916 & .928 & .904 & .925 & .913 & .220 & .088 \\
\hline
\end{tabular}

Standardized direct effects. The linear predictive model established the latent variable of test anxiety as a significant, positive predictor of both emotion-focused coping strategies (.11) and problem-focused coping strategies (.25). Moreover, this variable was a negative predictor of the latent variable self-regulation (.27). On the other hand, the latent variable self-regulation was a significant, positive predictor of problem-focused coping strategies (.46). Finally, the latent variable problem-focused coping strategies was a significant, positive predictor of emotion-focused coping strategies (.84). These standardized direct effects can be observed in Table 5. 
Table 5

Standardized direct effects.

\begin{tabular}{|c|c|c|c|c|}
\hline & ANXIETY & SR & PROB & EMOT \\
\hline$\overline{\mathrm{SR}}$ & -.274 & & & \\
\hline PROB & .253 & .456 & & \\
\hline EMOT & .110 & & .843 & \\
\hline taiemoc & .851 & & & \\
\hline taipreoc & .964 & & & \\
\hline$\overline{\text { GOALS }}$ & & .802 & & \\
\hline PERSEVERANCE & & .546 & & \\
\hline DECISIONS & & .257 & & \\
\hline LRNG MISTAKES & & .389 & & \\
\hline EECD2F1-Communicating feelings and social support & & & .729 & \\
\hline EECD2F2-Self-instructions & & & .853 & \\
\hline EECD2F3-Positive reappraisal and firmness & & & .815 & \\
\hline EECD2F4-Help seeking & & & .802 & \\
\hline EECD2F5-Seeking alternative reinforcement & & & .898 & \\
\hline EECD1F1-Preparing for the worst & & & & .889 \\
\hline EECD1F2-Reducing anxiety and avoidance & & & & .901 \\
\hline EECD1F3-Fantasy distraction & & & & .873 \\
\hline EECD1F4-Resigned acceptance & & & & .859 \\
\hline EECD1F5-Emotional venting and isolation & & & & .906 \\
\hline
\end{tabular}

Standardized indirect effects. The model also showed indirect predictions between variables. The predictive linear model established that the latent variable self-regulation was a significant positive predictor of emotion-focused coping strategies (.38). Furthermore, the latent variable test anxiety held significant, positive relations with all the factors of the coping strategies variable, while maintaining significant, negative relations with all the factors of the self-regulation variable. Finally, the latent variable self-regulation held significant, positive relationships with all the factors of the coping strategies variable. These standardized indirect effects can be observed in Table 6 .

Table 6

Standardized indirect effects.

\begin{tabular}{|c|c|c|c|c|}
\hline & ANXIETY & SR & PROB & EMOT \\
\hline \multicolumn{5}{|l|}{$\overline{\mathrm{SR}}$} \\
\hline PROB & -.125 & & & \\
\hline EMOT & .108 & .384 & & \\
\hline \multicolumn{5}{|l|}{ taiemoc } \\
\hline \multicolumn{5}{|l|}{ taipreoc } \\
\hline GOALS & -.220 & & & \\
\hline PERSEVERANCE & -.150 & & & \\
\hline DECISIONS & -.070 & & & \\
\hline LRNG MISTAKES & -.107 & & & \\
\hline EECD2F1-Communicating feelings and social support & .094 & .332 & & \\
\hline EECD2F2-Self-instructions & .109 & .388 & & \\
\hline EECD2F3-Positive reappraisal and firmness & .105 & .371 & & \\
\hline EECD2F4-Help seeking & .103 & .365 & & \\
\hline EECD2F5-Seeking alternative reinforcement & .115 & .409 & & \\
\hline EECD1F1-Preparing for the worst & .194 & .342 & .750 & \\
\hline EECD1F2-Reducing anxiety and avoidance & .197 & .346 & .760 & \\
\hline EECD1F3-Fantasy distraction & .191 & .335 & .736 & \\
\hline EECD1F4-Resigned acceptance & .188 & .330 & .725 & \\
\hline EECD1F5-Emotional venting and isolation & .198 & .348 & .764 & \\
\hline
\end{tabular}

Note: ANXIETY = Test anxiety; SR = Self-regulation; PROB = problem-focused coping strategies; EMOT = emotion-focused coping strategies 


\section{Discussion and Conclusions}

In general terms, in the light of the research findings, we can state that many of the hypothesized relationships between the study variables were fulfilled, while some did not appear and others appeared with less intensity than expected. At the same time, there were interesting findings between certain dimensions and factors that make up the study variables, helping to better explain the complex relationships that occur in processes of learning under stress.

Regarding Hypothesis 1, we may confirm that there are both association and interdependence relationships between the variables of test anxiety and personal self-regulation. These relationships suggest that subjects with greater anxiety do less in the way of self-regulating, especially those who are high in the emotionality factor of anxiety. More specifically, anxiety played a noteworthy role in decision making, given that both emotionality and (especially) worry, typical of anxiety, act as blockers to decision making, easily leading to avoidance and procrastination behaviors. These findings are consistent with other recent findings in the scientific literature, where high levels of anxiety and procrastination were related to low levels of self-regulation (Garzón-Umerenkova et al., 2018; Pichardo et al., 2018; Yerdelen et al., 2016).

As for Hypothesis 2, we may also confirm that there are loose relationships between test anxiety and coping strategies, even if the inferential analyses did not confirm these relationships in every case. The relationship between the two variables has already been verified in different contexts (Szabo et al., 2016). Unlike in the first hypothesis, the worry factor of anxiety in this case seems to be the influence toward greater use of strategies for coping with stress. It is possible that subjects who worry more experience greater stress, and this in turn makes them apply more strategies for coping with stress; subjects who worry less may simply find it unnecessary to do so. However, it is important to point out that the coping strategies proven to be more closely linked to high anxiety groups are emotion-focused: resigned acceptance and emotional venting/isolation. The latter strategy types are the most maladaptive in professional examination candidates, both for their emotion outcomes and their performance outcomes (de la Fuente, García-Torrecillas et al., 2015).

Finally, with respect to Hypothesis 3, while the expected relationships between the total variables personal self-regulation and stress coping strategies were not observed, both association and especially interdependence relationships were verified with one of the factors of personal self-regulation (goals). Indeed, subjects that set clear goals also seem to use more strategies for controlling stress; in particular, they use more problem-focused strategies. These subjects are characterized specifically by such behaviors as distraction, emotional venting, self-instructions, help-seeking, and seeking alternative reinforcement: the first two aimed at controlling the symptoms of stress, and the last three for controlling the problems that cause the stress. From all this, it can be concluded that goals play a crucial role, something that has previously been endorsed by the scientific literature (Ranellucci et al., 2015). In this case, goal-setting guides the subject to not only actively combat stress, but to do so in the best possible way, that is, by focusing on the search for solutions.

Regarding Hypothesis 4, we confirmed the existence of structural predictive relationships between the research variables. Direct and indirect effects confirmed that the test anxiety variable is a negative predictor of personal self-regulation and a positive predictor of stress coping strategies, more strongly so in the case of problem-focused strategies (GarzónUmerenkova et al., 2018; Pichardo et al., 2018; Szabo et al., 2016; Yerdelen et al., 2016). These findings confirm, at a fundamental level, the relationships expressed in the first two hypothesis. In contrast to our discussion of the third hypothesis, structural analysis did confirm a positive relationship, in general terms, between personal self-regulation and stress coping strategies, through direct effects for the problemfocused strategies and indirect effects for the emotionfocused strategies. In this regard, behaviors typical of selfregulation can be considered signs that indicate the use of more adaptive strategies for coping with stressful learning situations. The implied result is not only reduced risk of dropout in preparing for high-stakes tests such as these, but also improved performance (Garzón-Umerenkova et al., 2018; Pichardo et al., 2018).

\section{Limitations}

This investigation has certain sample limitations, both quantitatively (number of participants) and qualitatively (gender representation). The gender variable, precisely, has been related to anxiety and stress in several studies (Kosmala-Anderson \& Wallace, 2007), as well as with coping strategies (Guszkowska et al., 2016) and with certain factors of personal self-regulation (Garzón-Umerenkova et al., 2017). In addition, certain other variables could have been controlled, such as the number of times that subjects had attempted the exam, due to its possible influence on test anxiety and/or how this may have prompted learning in selfregulation and coping strategies.

\section{Implications in Educational Psychology}

One of the implications of this research is the desirability of systematic classroom work on all levels of self-regulation and coping strategies, focusing on aspects like decision making and goals. These have proven to be important for the use of coping strategies that focus on problem solving, thus increasing one's competency for learning in stressful contexts and promoting academic success (Thomas et al., 2017).

Another helpful measure would be to develop procedures and instruments for early identification of students with greater risk of developing high anxiety, and the situations where this is most likely to be appear. These students could be targeted in the implementation of contextualized 
stress management programs that work on problem solving strategies, in order to avoid maladaptive behaviors like dropping out or procrastination (Tapia et al., 2016), and excessive focus on emotions.

\section{Future lines for research}

First of all, the present study could be replicated using a larger sample, or with better gender representation, an aspect where there may be differences in variables like test anxiety and stress coping strategies (Guszkowska et al., 2016). Likewise, as expressed in the limitations section, certain other sociodemographic variables of the sample could be controlled, or the analyses could be further expanded. In this regard, variables can be selected or expanded based on the CSLPS Competency Model (de la Fuente, 2015; de la Fuente et al., 2014).

Second, new research studies could be designed to verify relationships where the effects were not as strong as expected. For example, there could be further inquiry into the

\section{References}

Alt, D. (2015). Assessing the contribution of a constructivist learning environment to academic self-efficacy in higher education. Learning Environments Research, 18(1), 47-67. https://doi.org/10.1007/s10984-0159174-5

Ariani, D. W. (2016). Why do I Study? The Mediating Effect of Motivation and Self-Regulation on Student Performance. Business, Management and Education, 14(2), 153-178. https://doi.org/10.3846/bme.2016.329

Banerjee, Y., Akhras, A., Khamis, A. H., Alsheikh-Ali, A., \& Davis, D. (2019). Investigating the Relationship Between Resilience, StressCoping Strategies, and Learning Approaches to Predict Academic Performance in Undergraduate Medical Students: Protocol for a Proof-ofConcept Study. JMIR Res Protoc, 8(9): e14677, 1-12. https://doi.org/10.2196/14677

Brown, J. M. (1998). Self-regulation and the addictive behaviors. In W. R. Miller \& N. Heather (Eds.), Treating Addictive Behaviors (2nd Ed., pp. 6173). New York, NY: Plenum Press. https://doi.org/10.1007/978-14899-1934-2_5

Brown, J. M., Miller, W. R., \& Lawendowski, L. A. (1999). The SelfRegulation Questionnaire. In L. Vandecreek \& T. L. Jackson (Eds.), Innovations in clinical practice: A source book (Vol. 17., pp. 281-293). Sarasota. FL: Professional Resources Press.

Burdwood, E. N., Infantolino, Z. P., Crocker, L. D., Spielberg, J. M., Banich, M. T., Miller, G. A., \& Heller, W. (2016). Resting-state functional connectivity differentiates anxious apprehension and anxious

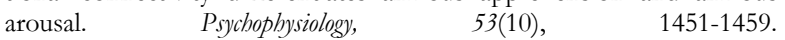
https://doi.org/10.1111/psyp.12696

Chorot, P., \& Sandín, B. (1993). Escala de Estrategias de Coping Revisado (EECR). [Revised Coping Strategies Scale]. Madrid, Spain: UNED.

Concerto, C., Patel, D., Infortuna, C., Chusid, E., Muscatello, M. R., Bruno, A., Zoccali, R. A., Aguglia, E. \& Battaglia, F. (2017). Academic stress disrupts cortical plasticity in graduate students. Stress, 20(2), 212-216. https://doi.org/10.1080/10253890.2017.1301424

Cote, L. P., \& García, A. M. (2016). Stress as a limiting factor in the decision-making process: a review on gender differences. Avances en Psicologia Latinoamericana, 34(1), 19-28. https://doi.org/10.12804/apl34.1.2016.02

de la Fuente, J. (2014). Confirmatory Structural Equation Model of Coping Strategies Scale (EEC). University of Almería.

de la Fuente, J. (2015). Competency for studying, learning, and performing under stress. Almería, Spain: Education \& Psychology I+D+i. relationships between test anxiety and coping strategies (Kavanagh et al., 2016), or between self-regulation and these coping behaviors (de la Fuente, 2017). This inquiry could serve to confirm relationships between factors that were significant here, like worry and goals, and also to determine the influence of the remaining factors.

Finally, in the line of the Educational Psychology implications, one could investigate the effectiveness of different screening procedures and instruments for identifying subjects with a tendency to develop high anxiety, or the effectiveness of programs in self-regulation and in coping strategies for high-performance situations with stressful contexts, such as when preparing for selective professional examinations.

Funding.- R\&D Project PGC2018-094672-B-I00, University of Navarra (Ministry of Science and Education, Spain); R \& D Project UAL18 SEJ-DO31-A-FEDER, University of Almería, Spain (European Social Fund).

http:/ /www.mitienda.investigacion-

psicopedagogica.org/espanol/ seccion.php?idsec $=13 \&$ \&idprod $=23$

de la Fuente, J. (2017). Theory of Self- vs. Externally-Regulated LearningTM. Fundamentals, Evidence, and Applicability. Frontiers in Psychology, 8(1675), 1-14. https://doi.org/10.3389/fpsyg.2017.01675

de la Fuente-Arias, J. \& Amate-Romera, J. (2019). Unpleasant past experience as a determinant of cognitive, behavioral and physiological responses to academic stress in professional examination candidates. $A n$ nals of Psychology, $\quad 35(3), \quad 472-482$. https://doi.org/10.6018/analesps.35.3.323101

de la Fuente, J., Amate, J. \& Sander, P. (2018). Relationships between cognitive strategies, motivational strategies and academic stress in professional examination candidates. Electronic Journal of Research in Educational 16(2),

345-365. http://ojs.ual.es/ojs/index.php/EJREP/article/view/2097

de la Fuente, J., Fernández-Cabezas, M., Cambil, M., Vera, M. M., González-Torres, M. C., \& Artuch-Garde, R. (2017). Linear relationship between resilience, learning approaches, and coping strategies to predict achievement in undergraduate students. Frontiers in Psychology, 8(1039), 1-13. https://doi.org/10.3389/ fpsyg.2017.01039

de la Fuente, J., García-Torrecillas, J. M., \& Rodríguez-Vargas, S. (2015). The relationship between coping strategies, test anxiety, and burnoutengagement behavior in university undergraduates. In M. Bachman (Ed.), Coping Strategies and Health (pp. 27-44). New York, NY: Nova Publisher.

de la Fuente, J., Justicia F., \& Berbén (2007). Expert learning and selfregulated learning. In F. Justicia, E. Fernández, \& M. C. Pichardo. Handbook of educational and developmental psychology (Vol. 1., pp. 509-531). Archidona, Spain: Aljibe.

de la Fuente, J., López, M., Vera, M. M., Martínez-Vicente, J. M., \& Zapata, L. (2017). Personal self-regulation, learning approaches, resilience and test anxiety in psychology students. Estud. Educ., 32, 9-26. https://doi.org/10.15581/004.32.9-26

de la Fuente, J., López, M., Zapata, L., Martínez-Vicente, J. M., Mariano, M., Solinas, G. \& Fadda, S. (2014). Competency to study and learn in stressful contexts: fundamentals of the "e-Coping with Academic Stress" utility. Electronic Journal of Research in Educational Psychology, 12(3), 717-746. https://doi.org/10.14204/ejrep.34.14034

de la Fuente, J., Sander, P., López, M., \& Putwain, D. (2015). The relationship between academic confidence and learning approaches, selfregulation, stress coping and resilience in university undergraduates. In 
A. M. Columbus (Ed.). Advances in Psychology Research (Vol. 112, pp. 2547). New York, NY: Nova Publisher.

de la Fuente, J., Sander, P., Martínez-Vicente, J. M., Vera, M., Garzón, A., \& Fadda, S. (2017). Combined Effect of Levels in Personal SelfRegulation and Regulatory Teaching on Meta-Cognitive, on MetaMotivational, and on Academic Achievement Variables in Undergraduate Students. Frontiers in Psychology, 8(232), 1-19. https://doi.org/10.3389/fpsyg.2017.00232

de la Fuente, J., Zapata, L., \& Martínez-Vicente, J. M. (2016). Effects of level of personal self-regulation and different contexts of stress on coping strategies in higher education. In C. H. Gallagher (Ed.). Academic Performance: Student Expectations, Environmental Factors and Impacts on Health (pp. 77-90). New York: Nova Publisher.

de Ridder, D. T. D., Lensvelt-Mulders, G., Finkenauer, C., Stock, F. M., \& Baumeister, R. F. (2012). Taking stock of self-control: A meta-analysis of how trait self-control relates to a wide range of behaviors. Personality and Social Psychology Review, 16(1), 76-99. https://doi.org/10.1177/1088868311418749

Duckworth, A. L., Quinn, P. D., \& Tsukayama, E. (2012). What no child left behind leaves behind: The roles of IQ and self-control in predicting standardized achievement test scores and report card grades. Journal of Educational Psychology, 104(2), 439-451. https://doi.org/10.1037/a0026280

Escolar, M. C., \& Serrano, I. (2014). Definition of the test anxiety construct in university students. Ansiedad y Estrés, 20(2-3), 165-180. http://www.ansiedadyestres.org/content/vol-20_2-3-pp-165-180-2014

Garzón-Umerenkova, A., de la Fuente, J., Amate, J., Paoloni, P. V., Fadda, S., \& Pérez, J. F. (2018). A Linear Empirical Model of Self-Regulation on Flourishing, Health, Procrastination, and Achievement, Among University Students. Frontiers in Psychology, 9(536), 1-12. https://doi.org/10.3389/fpsyg.2018.00536

Garzón-Umerenkova, A., de la Fuente, J., Martínez-Vicente, J. M., Zapata, L., Pichardo, M. C., \& García-Berbén, A. B. (2017). Validation of the Spanish Short Self-Regulation Questionnaire (SSSRQ) through Rasch Analysis. Frontiers in Psychology, 8(276), 1-11. https://doi.org/10.3389/fpsyg.2017.00276

Guszkowska, M., Zagórska-Pachucka, A., Kuk, A., \& Skwarek, K. (2016). Gender as a factor in differentiating strategies of coping with stress used by physical education students. Health Psychology Report, 4(3), 237245. https://doi.org/10.5114/hpr.2016.57681

Karoly, P., Boekaerts, M., \& Maes, S. (2005). Toward consensus in the psychology of self-regulation: How far have we come? How far do we have yet to travel? Applied Psychology: An International Review, 54(2), 300311. https://doi.org/10.1111/j.1464-0597.2005.00211.x

Kavanagh, B. E., Ziino, S. A., \& Mesagno, C. (2016). A Comparative Investigation of Test Anxiety, Coping Strategies and Perfectionism between Australian and United States Students. North American Journal of Psychology, 18(3), 555-569. https://www.researchgate.net/publication/317022591_A_comparative _investigation_of_test_anxiety_coping_strategies_and_perfectionism_b etween_Australian_and_United_States_students

Kosmala-Anderson, J., \& Wallace, L. M. (2007). Gender differences in the psychosomatic reactions of students subjected to examination stress. Electronic Journal of Research in Educational Psychology, 5(2), 325-348. http://www.investigacion-psicopedagogica.org/revista/new/index.php

Lazarus, R. S., \& Folkman, S. (1984). Stress, appraisal and coping. New York: Springer.

Mehmet, A. K., \& Watson, J. C. (2017). Examining associations among achievement motivation, locus of control, academic stress, and life satisfaction: A comparison of U.S. and international undergraduate stu- dents. Personality and Individual Differences, 111(1), 106-110. https://doi.org/10.1016/j.paid.2017.02.006

Modecki, K. L., Zimmer-Gembeck, M. J., \& Guerra, N. (2017). Emotion regulation, coping, and decision making: three linked skills for preventing externalizing problems in adolescence. Child Development, $88(2), 417-$ 426. https://doi.org/10.1111/cdev.12734

Muis, K. R., Chevrier, M., \& Singh, C. A. (2018). The role of epistemic emotions in personal epistemology and self-regulated learning. Educational Psychologist, $53(3)$

$1-20$. https://doi.org/10.1080/00461520.2017.1421465

Nielsen, M. B., \& Knardahl, S. (2014). Coping strategies: a prospective study of patterns, stability, and relationships with psychological distress. Scandinavian Journal of Psychology, 55(2), 142-150. https://doi.org/10.1111/sjop.12103

Pekrun, R. (2016). Academic emotions. In K. R. Wentzel \& D. B. Miele (Ed.). Handbook of Motivation at School (pp. 120-144). New York: Taylor \& Francis. https://www.routledgehandbooks.com/doi/10.4324/ 9781315773384.ch7

Pichardo, M. C., Cano, F., Garzón-Umerenkova, A., de la Fuente, J., Peralta-Sánchez, F. J., \& Amate-Romera, J. (2018). Self-Regulation Questionnaire (SRQ) in Spanish Adolescents: Factor Structure and Rasch Analysis. Frontiers in Psychology, 9(1370), 1-14. https://doi.org/10.3389/fpsyg.2018.01370

Pichardo, M. C., Justicia, F., de la Fuente, J., Martínez-Vicente, J. M., \& Berbén, A. B. (2014). Factor structure of the self-regulation questionnaire (SRQ) at Spanish Universities. The Spanish Journal of Psychology, 17(E62), 1-8. https://doi.org/10.1017/sjp.2014.63

Putwain, D., Daly, A., Chamberlain, S., \& Sadreddini, S. (2015). Academically buoyant students are less anxious about and perform better in highstakes examinations. British Journal of Educational Psychology, 85(3), 247 263. https://doi.org/10.1111/bjep.12068

Ranellucci, J., Hall, N. C., \& Goetz, T. (2015). Achievement goals, emotions, learning, and performance: A process model. Motivation Science, 1(2), 98-120. https://doi.org/10.1037/mot0000014

Sarason, I. G. (1980). Test anxiety: Theory, research and application. Hillsdale, N.J.: Erlbaum. https://doi.org/10.1007/978-1-4899-2504-6_16

Szabo, A., Ward, C., \& Jose, P. E. (2016). Uprooting stress, coping, and anxiety: A longitudinal study of international students. International Jour nal of Stress Management, 23(2), 190-208. https://doi.org/10.1037/a0039771

Tabachnick, B. G., \& Fidell, L. S. (2001). Principal components and factor analysis. Using multivariate statistics, 4(1), 582-633.

Tapia, M. A., Becerra, M., \& Borja, L. E. (2016). Situations that create anxiety in dentistry students. Journal of Behavior, Health \& Social Issues, 8(2), 35 41. https://doi.org/10.1016/j.jbhsi.2016.11.004

Thomas, C. L., Cassady, J. C., \& Heller, M. L. (2017). The influence of emotional intelligence, cognitive test anxiety, and coping strategies on undergraduate academic performance. Learning and Individual Differences, 55 , 40-48. https://doi.org/10.1016/j.lindif.2017.03.001

Torre, N. O., \& Vidal, O. F. (2017). Constructivist models of learning in education al programs. Barcelona, Spain: OmniaScience. https://doi.org/10.3926/oms.367

Yager, H. (2008). Examination of the Psychometric Properties of the Test Anxiety Inventory for Children and Adolescents (TAICA) with a Sample of Hispanic and White Adolescents. Michigan: ProQuest.

Yerdelen, S., McCaffrey, A., \& Klassen, R. M. (2016). Longitudinal Examination of Procrastination and Anxiety, and their Relation to SelfEfficacy for Self-Regulated Learning: Latent Growth Curve Modeling. Educational Sciences: Theory and Practice, 16(1), 5-22. https://doi.org/10.12738/estp.2016.1.0108 